\title{
Experimental Set up of Two Closed Loop Pulsating Heat Pipe (CLPHP) with Water base Fluids
}

\author{
N SanthiSree, N V V S Sudheer, P.Bhramara
}

\begin{abstract}
Heat pipes are deliberated to be effective heat dissipation devices compared to other types of heat sinks due to their high effective thermal conductivity. Because of the flexibility in the design and layout of heat pipe turns along the heat source, pulsating heat pipes have gained popularity. One of the parameters that have the mainimpact on the presentation of CLPHP is the thermo physical properties of the working fluid. The properties of the working fluid affect the temperature difference between the evaporator and the condenser which in turn affect the thermal resistance of the CLPHP. In this connection, the influence of different working fluids is experimentally investigated on a two loop CLPHP, varying the evaporator heat flux. Pure fluids, viz., water, acetone, benzene and binary mixture, viz., Acetone-water and Benzene-water are utilized on working fluids. The heat input considered at the evaporator is $32 \mathrm{~W}, 48 \mathrm{~W}$ and $60 \mathrm{~W}$. The filling ratio is kept as 50 $\%$. The results show that among the working fluids considered for the study, acetone exhibits least thermal resistance among the pure fluids at all heat fluxes considered in the analysis, while Acetone-water mixture has exhibited least thermal resistance among the water based mixtures.
\end{abstract}

Keywords: CLPHP, Condenser temperature, Evaporator temperature, Filling Ratio, Thermal resistance, Working Fluid.

\section{INTRODUCTION}

Thermal management of micro devices, modelling of small scale heat transfer devices become an important criteria for electronics and miniaturization. Thermally speaking for such challenging problems, pulsating heat pipe (PHP) provides a hopeful solution. Among PHP's mainly a closed loop pulsating heat pipe will be aimproved solution than an open loop device. PHP is essentially a small pipe filled with working fluid. It comprisesof a simple meandering tube of capillary dimensions bynumerous U-turns and connected end to end.The working fluid is filled in the tube after partial evacuating of the tube. PHP is a two phase heat transfer device consists of a heating zone at the bottom end, cold zone at the other end and an optional adiabatic zone [1]. One end of this tube bundle receives heat from the electronic system.Between the vapour segments, the plugs or slugs are formed by the liquid in the pipe [2].The pressure difference which is caused due to the evaporation and absorption of part of the liquid upon encountering heat will be driving force for the movements of slugs and plugs in the pipe flow.Present fluid used in operating pressure maintained privileged the pulsating heat pipe be governed by the operating temperature of the heat pipe i.e. the amount of heat energy released by the electronic system. Even though PHP systems look simple, its working mechanism is relativelycomplex. It involves multi- physics phenomena such as Two-phase flow, phase change, Evaporationcondensation phenomena, and thermo-hydrodynamics like bubble flow, bubble dynamics and others [3]

\subsection{Principle of Operation}

Starting with the thermodynamic purpose of view, PHP will be an engine, but the work is specifically utilized to produce the oscillations andphasemodification high temperature exchange [4]. For a typical high power PHP that worth of effort prepared starting with An PHP may be higher over accepted heat channel. Openly, the PHP need high thermal effectiveness over a traditional high temperature pipe, which clarifies the reason antypocal PHP could accomplish high temperature transport capability[5].For operation it neither contains mechanical moving parts like convectional heat pipe nor does any electrical power. PHP not contain any wick structure in it so there is no come again of the working fluid from condenser to evaporator. Due to in equilibrium heat transfer, there exists a small temperature difference among the individual ' $U$ ' bends. The pressure drop connectedby means of each sub-section is dissimilar as the volumetric distribution of working fluid is not uniform throughout the tube which causes flow instabilities and pressure imbalances [6]. And an equilibrium state is created in the pipe due to the condensation process at one end and bubble generation process at the heating end. With the combination of sensible and latent heat transfer, the heat is transmission in the tube. These are generally of light weight, very fast response, low fabrication cost and simple design.

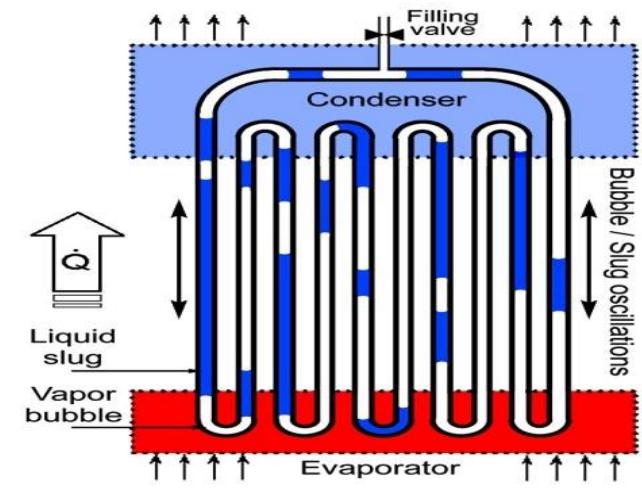

Fig 1: Closed loop PHP ${ }^{[3]}$

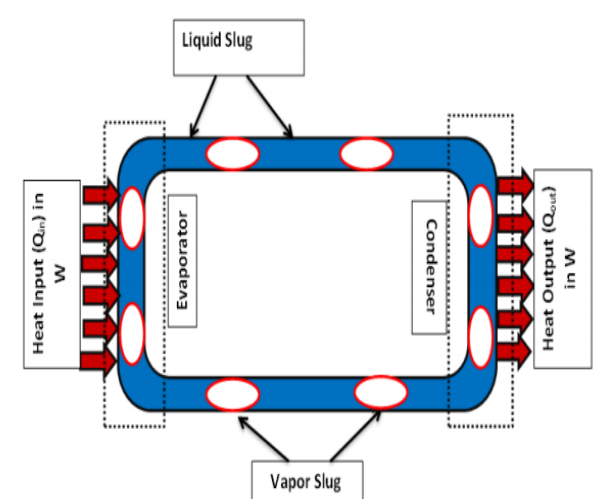

Fig 2. Operating Mechanism 


\section{Experimental Set up of Two Closed Loop Pulsating Heat Pipe (CLPHP) with Water base Fluids}

\subsection{Parameters Affecting the presentation of Closed Loop PHP}

The presentation of PHP is strongly affected by many parameters including operational, geometries and physical parameters.
$>$ Working fluid
$>$ Internal diameter
$>$ Filling ratio
$>$ Orientation of Tubes
$>$ Heat input
$>$ Number of turns and Inclination angle.

The two phase flow in CLPHP is mainly dependent on the operational fluid used. The operating vapour temperature is the main deliberation in the assortment of appropriate working fluid. In general in the approximate range of 50 to $150^{\circ} \mathrm{C}$ most of the working fluids will exist. Thermal stability, reasonable vapour pressure, lower values of liquid and vapour viscosities and high thermal conductivity are variousmajor requirements for selection of operational fluidSince evaporator to condenser to carry the given heat input the fluid must have a high thermal conductivity. Water is safe working fluid. It is having high latent heat which results in low pressure drop and high power[7].Compatibility with tube material is also one of the most important consideration for working fluid selection.

The pulsating action in the CLPHP is possible only to a certain range of internal diameter values. The buoyancy and surface tension affects the movement and appearance of the liquid slug in the tube critical diameter is given by the following formula

$$
\text { Dcri } \leq 2 \sqrt{\sigma} /(g \times(\text { liq }-\rho v a p))
$$

Heat input directly affects the performance of PHP. The pressure difference inside the tube due to slug and plugs increases with higher heat flux rates .Dynamics of bubbles formed inside the tube, size of the bubble and agglomeration of bubbles are some of the effects of heat input [8].For better working of CLPHP s, the tube must be partially filled. In the present analysis 50\% filling ratio is considered [9]. CLPHP's will be working at 40 to $60 \%$ of filling ratio. Horizontal orientation of tubes does not give as good a performance as vertical orientation. Vertical orientation with more number of turns improves the performance [10] .To increase the pulsating motion inside the device it is always necessary to have an optimum number of turns [11]. With more number of turns the pressure drop will increase which give rise to a better formation of plugs and slugs [12]. If the number of turns is less than a significantworth the whole of the evaporators packed with vapour bubble only and the rest of the PHP is with liquid. [13].

In the present study vertical orientation is considered. An experiment is conducted with working fluids viz. water, acetone, and benzene as pure fluids, also Acetone-water, Benzene-water as binary mixtures. The slugs and plugs of fluid flow gives the changes in temperatures at evaporator and condenser sections for different heat input values $(32 \mathrm{~W}$, $48 \mathrm{~W}, 60 \mathrm{~W})$. By measuring these temperatures the resistance characteristics of working fluids had been investigated.
II.

\section{INVESTIGATIONAL ARRANGEMENTS:}

Here the test arrangement is about CLPHP comprises from an evaporator, condenser and adiabatic segment. Likewise comprises aindividualcontroller board for quantifyingappliancesas demonstrated over fig. Those CLPHP verifiedbelow experimentation comprises of 2loopsof tube measurements of copper with (I. D: 2. 0mm, o. D: 3. 6mm). The setup containspower supply unit, information logger systemabout 16 channels and cooling system. The measurementsof evaporator, adiabatic and condenser segment aregiven by $42 \mathrm{~mm}, 170 \mathrm{~mm}$ and $50 \mathrm{~mm}$ individually. That distance among the legs might have been $20 \mathrm{~mm}$ and overall size of CLPHP will be $60 \mathrm{~mm} \times 262 \mathrm{~mm}$. [14-16].

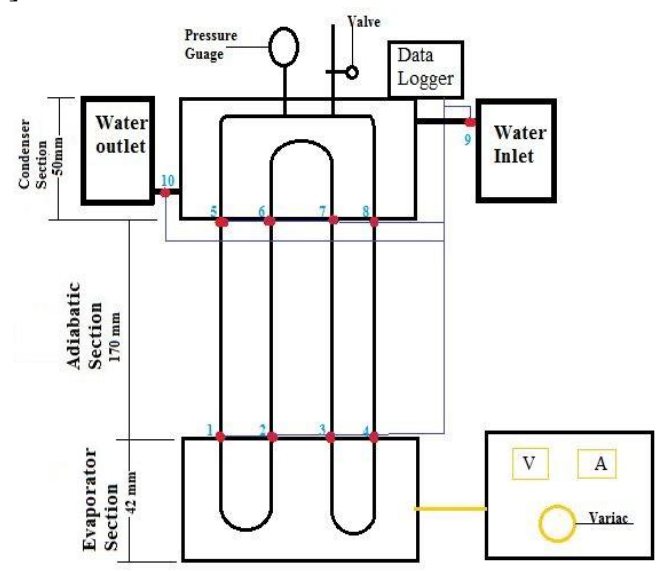

Fig:3Schematic Diagram

The heating energy of the evaporator is given by flat plates thatare associated with variacfor the warming controller may be supplied of the evaporator. That adiabatic area may be great insulated by glass wool. To get those vacuum in the tube, a responding vacuum pump will be associated with filling valve, will make vacuum level not less than $70 \mathrm{~cm}$ for $\mathrm{Hg}$. The filing ratio (FR) $50 \%$ has been administered. Those PHP position might have been preserved at vertical base heat mode (BHM). Heat is eliminated in the condenser area by giving work to a cooling shower by water. Condenser block is made from acrylic sheet consisting measure about $125125 \times 75 \times 65 \mathrm{~mm}^{3}$.

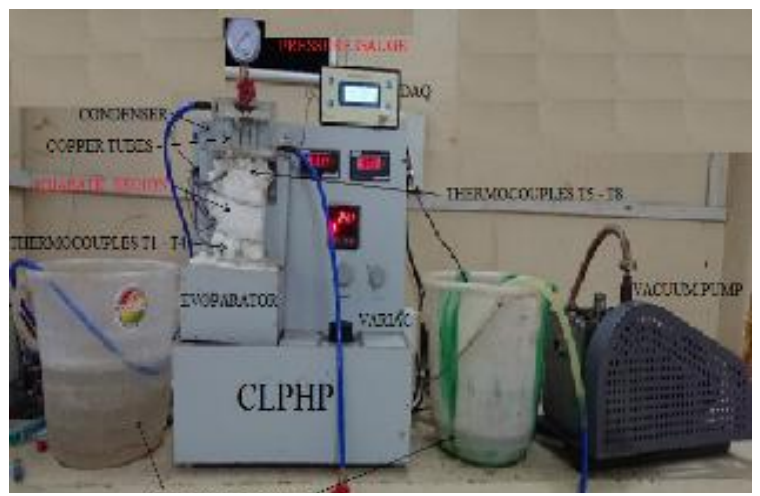

Fig.4 InvestigationalArrangement 
Those thermocouples need aid appended with divider with tube. 4 thermocouples (T1-T4) are symmetrically connected recently over the evaporator unit and 4 thermocouples (T5T8) recently underneath that condenser segment. Previously, addition, particular case thermocouple each toward inlet (T9) and outlet (T10) of the condenser might have been utilized with monitor that temperature varies. The output of the thermocouples is connected to the data logger in which the values are recorded.By using evaporator and condenser temperatures for a given heat input thermal resistance is determined.

The Thermal Resistance of PHP is calculated by equation

$$
\mathrm{R}=\frac{\boldsymbol{T}_{e}-\boldsymbol{T}_{\boldsymbol{c}}}{\boldsymbol{Q}} \quad \mathrm{K} / \mathrm{W}
$$

\section{RESULTS}

\subsection{Water as working fluid.}

The experiment is conducted by considering water as working fluid .Heat is supplied by variac at different values namely 32, 48 and 60 watts. The values oftemperatures at evaporator and condenser for every 3 seconds obtained from data logger.The fig describes the phenomena of heat transfer considering working fluid as water at different heat inputs. It displays the difference of thermal resistance by evaporator and condenser temperature difference at $60 \mathrm{~W}$ heat load.

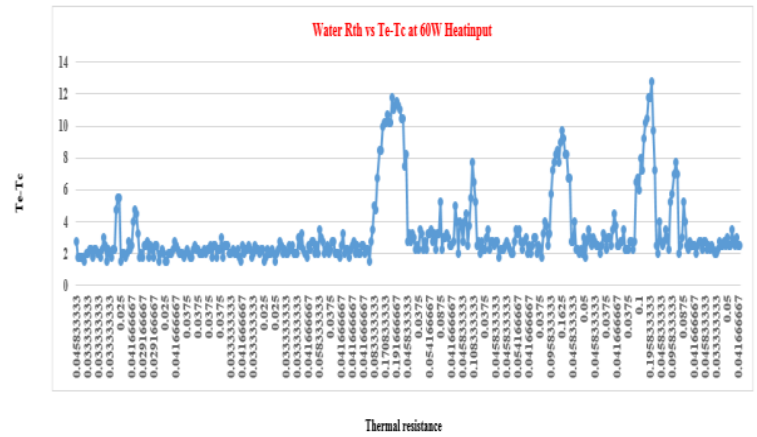

Fig 5 RthVsT ${ }_{\mathrm{e}}-\mathrm{T}_{\mathrm{c}}$ graph of Water at $50 \%$ fill ratio with $60 \mathrm{~W}$ heat load

3.2 Benzene-Water (75\%-25\%) as working fluid

The fig was obtained when Benzene-Water (binary mixture) is considered as working fluid at $60 \mathrm{~W}$ heat input. It shows the variation of thermal resistance with evaporator and condenser temperature difference at $60 \mathrm{~W}$ heat load.

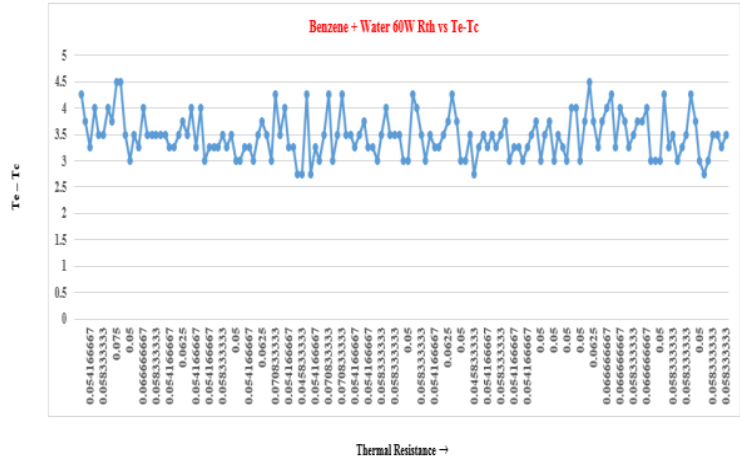

Fig.6RthVsTe-Tc graph of Benzene-water at 50\% fill ratio with $60 \mathrm{~W}$ heat load

3.3 Acetone as Working fluid

When Acetone as pure fluid is considered as working fluid the following curve is obtained at $60 \mathrm{~W}$ heat input. It displays the difference of thermal resistance by evaporator and condenser temperature difference at $60 \mathrm{w}$ heat.

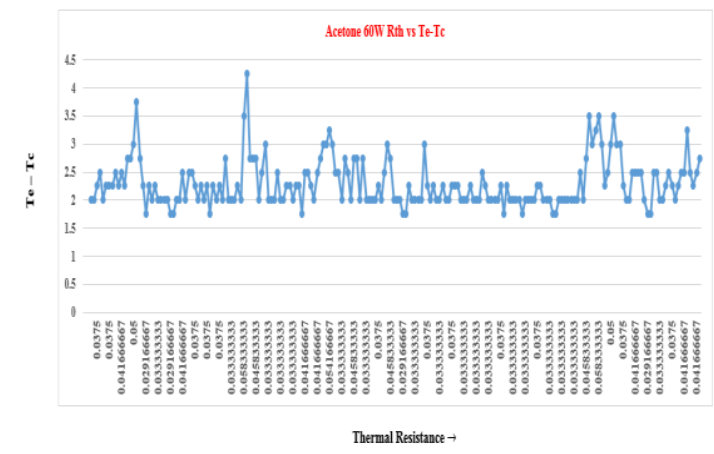

Fig.7 $\mathbf{R}_{\mathrm{th}}$ VsTe-Tc graph of Acetone at $50 \%$ fill ratio with 60W heat load

\subsection{Acetone-Water (75\%-25\%) as Working fluid}

The fig was obtained when Acetone-Water (binary mixture) is considered as working fluid at $60 \mathrm{~W}$ heat input. It shows the variation of thermal resistance with evaporator and condenser temperature difference at $60 \mathrm{~W}$ heat load.

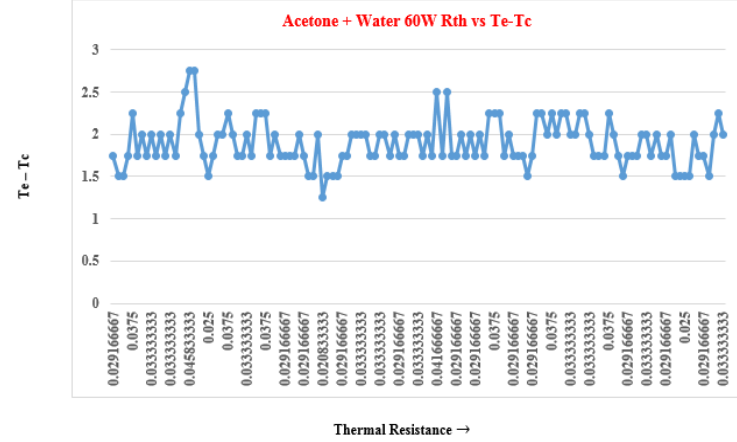

Fig.8 RthVsTe-Tc graph of Acetone-Water at 50\% fill ratio with $60 \mathrm{~W}$ heat load

Upon supplying heat input by the temperature of evaporator and condenser changes. This is described by considering acetone as aoperational fluid .The graphs are drawn for Temp Vs time at heat inputs $32 \mathrm{~W}, 48 \mathrm{~W}$, and $60 \mathrm{~W}$.

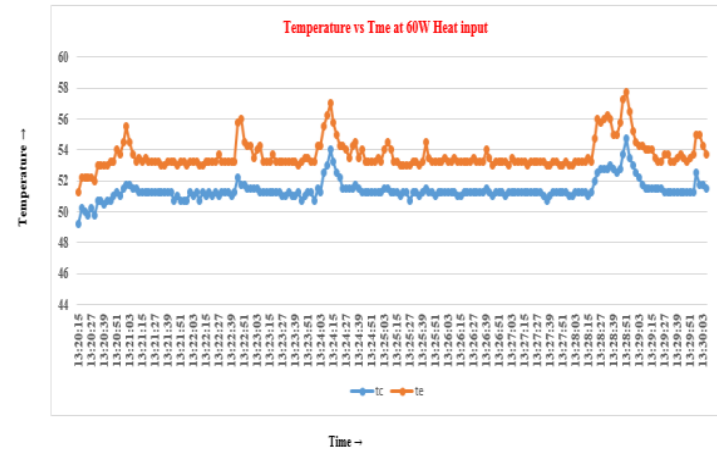

Fig.9 Temperature Vs Time graph of Acetone at $50 \%$ fill ratio with $60 \mathrm{~W}$ heat load 


\section{Experimental Set up of Two Closed Loop Pulsating Heat Pipe (CLPHP) with Water base Fluids}

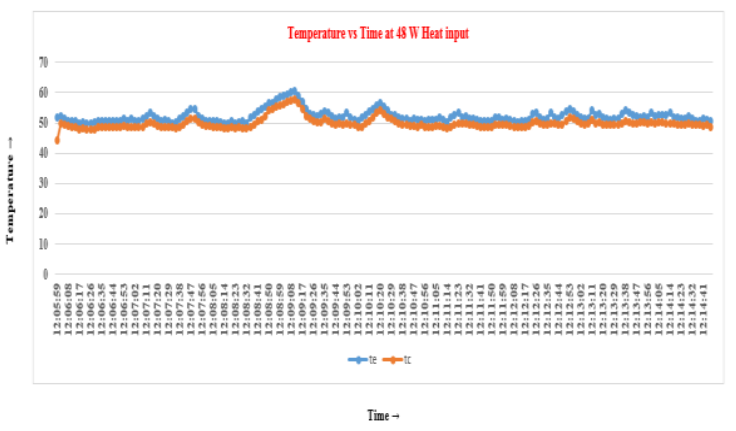

Fig.10 Temperature Vs Time graph of Acetone at 50\% fill ratio with $48 \mathrm{~W}$ heat load

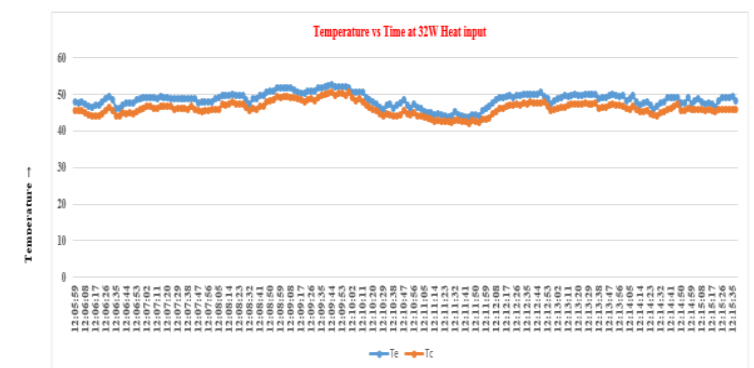

Time $\rightarrow$

Fig.11Temperature Vs Time graph of Acetone at $50 \%$ fill ratio with $32 \mathrm{~W}$ heat load

\section{DISCUSSIONS}

\section{Effect of working fluids on Thermal Resistance}

The evaporator and condenser temperatures are tabulated utilizing data logger and the corresponding graphs are drawn for different working fluids.

The graph drawn comparing thermal resistance of all working fluids that are taken for experimentation (i.e. Water, Acetone-Water (75\%-25\%), and Acetone, Benzenewater $(75 \%-25 \%)$ at different $32 \mathrm{~W}, 48 \mathrm{~W}$ and $60 \mathrm{~W}$ heat loads.

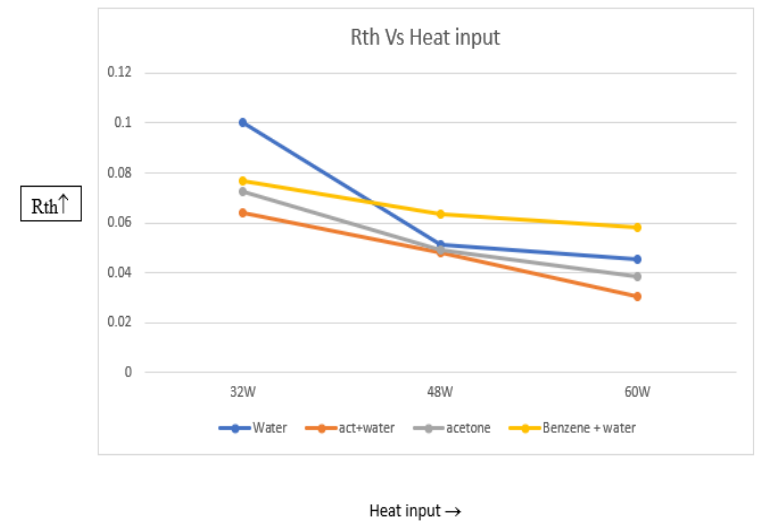

Fig.12RthVs Heat input of Water, Acetone-Water, Acetone, Benzene-Water of $50 \%$ fill ratio at $32 \mathrm{~W}, \mathbf{4 8 W}$, and 60W heat loads

By above experimental results the working fluids with azeotropic binary mixtures undergoes less thermal resistance than pure working fluid and also as heat input increases thermal resistance decreases.

\section{CONCLUSIONS}

The experimentation was conducted for different working fluids (water, acetone, acetone-water (75\%-25\%), benzenewater $(75 \%-25 \%))$ at different heat inputs $(32 \mathrm{~W}, 48 \mathrm{~W}, 60 \mathrm{~W}$ respectively).The variation of thermal resistance was observed. Starting with the results, it is concluded that work fluid is adequately carrying high temperature from evaporator area of the condenser region as demonstrated by those temperature change andflow of operationalfluids

- As heat load expands that temperature differentiate between those evaporator and more condenser areas rises.

- By increasing the heat flux, the resistance of CLPHP is observed to reduce for all working fluids.

- $\quad$ Among the pure fluids considered Acetone has shown the least thermal resistance

- Among the water based binary mixtures considered, acetone -water mixture has shown the least thermal resistance.

- The binary mixtures exhibited rather flat variation of thermal resistance by heat flux compared to the pure fluids.

- Among the two binary mixtures considered, benzene water mixture has exhibited less variation of thermal resistance with heat flux compared to that of acetone-water mixture.

- Thermal resistance is highest for Benzene+Water and least for Acetone+Water mixture when it is operating at $60 \mathrm{~W}$.

The experimentation is conducted at different heat inputs i.e. $32 \mathrm{~W}, 48 \mathrm{~W}, 60 \mathrm{~W}$ with different working fluids (water, acetone, acetone-water (75\%-25\%), benzene-water (75\%$25 \%)$ ) shows by increasing heat the input thermal resistance increases whereas value decreases.

\section{REFERENCES}

1. S. Khandekar, M. Groll, P. Charoensawaran and P. Terdtoon, "Pulsating Heat Pipes: Thermo-fluidic Characteristics and Comparative Study with Single Phase Thermosyphon" Proceedings of 12th International Heat Transfer Conference, Volume. 4, pp.459464(2002)

2. J. L. Xu, Y. X. Li and T. N. Wong, "High Speed Visualization of Closed Loop Pulsating Heat Pipe" International Journal of Heat and Mass Transfer 48(2005)

3. Akachi, H and Polášek F, "Pulsating Heat Pipes", 5th Int. Heat Pipe Symposium(1996)

4. Sameer Kandhekar and Manfred Groll, "On the Definition of Pulsating Heat Pipes-An Overview" Proc. 5th Minsk International Seminar, Minsk, Belarus.(2003)

5. S. Arabnejad, R. Rasoulian, M. B. Shafii, and Y. Saboohi, 2010, "Numerical Investigation of the Performance of a U-Shaped Pulsating Heat Pipe" Heat Transfer Engineering, Volume 31 (14), pages 11551184,(2010)

6. PramodR.Pachghare and AshishM.Mahalle, "Thermo-hydrodynamics of closed loop pulsating heat pipe: an experimental study" Journal of Mechanical Science and Technology 28, Volume 8, pages 33873394,(2014)

7. Mauro Mameli, Vincenzo Manno, SauroFilippeschi, Marco Marengo, "Thermal instability of a Closed Loop Pulsating Heat Pipe: Combined effect of orientation and filling ratio" Experimental Thermal and Fluid Science 59 
8. BhawnaVerma, Vijay Lakshmi Yadav and Kaushal Kumar Srivastava, "Experimental Studies on Thermal Performance of a Pulsating Heat Pipe with Methanol/DI Water" Journal of Electronics Cooling and Thermal Control, Volume 3, pages 27-34.(2013)

9. Vipul M. Patel and H. B. Mehta, "Influence of Gravity on the Performance of Closed Loop Pulsating Heat Pipe", 18 (1),(2016)

10. NitiKammuang-lue, PhrutSakulchangsatjatai and PraditTerdtoon,"Effect of Working Fluids on Thermal Characteristic of a Closed-Loop Pulsating Heat Pipe Heat Exchanger: A Case of Three Heat Dissipating Devices.(2012)

11. HonghaiYang, S.Khandekar, M.Groll, "Operational Limit of Closed Loop Pulsating Heat Pipes" Science Direct, Applied Thermal Engineering 28, (2008)

12. Brian Holley and Amir Faghri, ,"Analysis of pulsating heat pipe with capillary wick and varying channel diameter" International Journal of Heat and Mass Transfer 48,(2005)

13. Yuwen Zhang and Amir Faghri, "Heat Transfer in Pulsating Heat Pipe with Open End" International Journal of Heat and Mass Transfer 45, pages 755-764,(2002)

14. Mauro Mameli, Marco Marengo and Sameer Khandekar, "Local Heat Transfer Measurement and Thermal fluid Characterization of a Pulsating Heat pipe" International Journal of Thermal Sciences 75, pages140-152.(2014)

15. B. Y. Tong and T. N. Wong "Closed-Loop Pulsating Heat Pipe" Applied Thermal Engineering 21, pages 1845-1862(2001).

16. Dharmapal A Baitule and Pramod R Pachghare, "Experimental Analysis of Closed Loop Pulsating Heat Pipe with Variable Filling Ratio" Volume 2, No. 3. (2009). 